\title{
Dynamic Monitoring of Jiuzhaigou Earthquake Damaged Landscape Restoration Based on SBAS-InSAR
}

\author{
Maoying Ran1,2, Weihong Wang1,2, Hong Zhu1, Shihua Geng1,2, Weiqiang Wu1,2 \\ ${ }^{1}$ School of Environment and Resources, Southwest University of Science and Technology, Mianyang, China \\ ${ }^{2}$ Mianyang Science and Technology City Branch of National Remote Sensing Center, Mianyang, China \\ Email: 1c65764@163.com
}

How to cite this paper: Ran, M.Y., Wang, W.H., Zhu, H., Geng, S.H. and Wu, W.Q. (2021) Dynamic Monitoring of Jiuzhaigou Earthquake Damaged Landscape Restoration Based on SBAS-InSAR. Open Access Library Journal, 8: e7938.

https://doi.org/10.4236/oalib.1107938

Received: September 8, 2021

Accepted: September 27, 2021

Published: September 30, 2021

Copyright $\odot 2021$ by author(s) and Open Access Library Inc.

This work is licensed under the Creative Commons Attribution International License (CC BY 4.0).

http://creativecommons.org/licenses/by/4.0/

(c) (i) Open Access

\begin{abstract}
On August 8, 2017, Jiuzhaigou earthquake caused a large number of geological disasters in Jiuzhaigou scenic area, and many landscapes were seriously damaged. Sentinel-1A data from July 30, 2017 to January 28, 2020 are selected as the data source. SBAS-InSAR technology is used to obtain the settlement rate changes of Jiuzhaigou earthquake damaged core landscape Panda sea, Spark sea and Nuorilang waterfall, and dynamically monitor the restoration and conservation results of Jiuzhaigou. The results show that after the earthquake, the core landscape land subsidence occurs rapidly, and the settlement reaches $43 \mathrm{~mm}$. The settlement of spark sea and NuoRiLang waterfall is large, and the maximum settlement is $65 \mathrm{~mm}$. The three sites showed a downward trend, and the settlement rate decreased slowly and tended to be stable after repair. The effect of dynamic monitoring of Jiuzhaigou restoration and conservation is obvious, which provides a new method for landscape restoration and conservation monitoring of Jiuzhaigou scenic spots.
\end{abstract}

\section{Subject Areas}

Environmental Sciences, Geomorphology

\section{Keywords}

SBAS-InSAR, Jiuzhaigou, Landscape Restoration and Conservation, Dynamic Monitoring

\section{Introduction}

Jiuzhaigou scenic spot is located in the transition zone between two geomorphic units of Qinghai Tibet Plateau and Sichuan Basin, and in the south central part of 
Jiuzhaigou County, Aba Autonomous Prefecture, Sichuan Province. The terrain in this area is high in the South and low in the north. The terrain is complex. There are 68 peaks with an altitude of more than $4000 \mathrm{~m}$, the highest point of the basin is $4764 \mathrm{~m}$, the lowest point is $1996 \mathrm{~m}$, the height difference is about $2768 \mathrm{~m}$, the horizontal distance between the maximum height difference points is about $46 \mathrm{~km}$, and the average height difference of the whole basin is more than $1600 \mathrm{~m}$. At the same time, there are abundant plant resources and dense vegetation coverage. Jiuzhaigou has a complex geological environment, strong neotectonic movement, dominated by carbonate rocks, highly developed fold faults, and frequent natural disasters [1] [2]. The travertine located in Jiuzhaigou is one of the world's highest (2200 m - $2900 \mathrm{~m}$ ) vegetation, environmental temperature, and river basin travertine. At 21:19 on August 8, 2017, a magnitude 7.0 earthquake occurred in the Jiuzhaigou Scenic Area, Zhangzha Town, Jiuzhaigou County, with a focal depth of about $20 \mathrm{~km}$ [3]. Seismic activity not only induced a large number of disasters such as landslides and collapses in Jiuzhaigou Scenic Area, but also affected Jiuzhaigou's surface water flow, water level, vegetation, animals, topography and natural landscape to a certain extent.

The Jiuzhaigou earthquake caused the geological environment in a certain area to deteriorate, and the residential areas and scenic spots in the earthquake area suffered serious damage. After the earthquake, it mainly induced small and medium landslides and collapses, followed by the resurrection of some old landslides [4]. Many scholars have done a lot of research based on the disasters caused by the Jiuzhaigou earthquake. Yuan Maoke and others used 3S technology to study the sensitivity of Jiuzhaigou's post-earthquake ecological and geological environment [5]; Luo Luguang and others selected 16 combinations of landslide control and influencing factors to select Jiuzhaigou Earthquake landslides were evaluated [6]; Li Dong et al. used Sentinel-1A data to monitor the surface deformation of Jiuzhaigou [7]; this paper uses SBAS-InSAR technology to monitor the core seismic damage landscape that is repaired after the earthquake.

Interferometry Synthetic Aperture Radar (InSAR) technology breaks through the limitations of traditional monitoring methods, and realizes large-scale monitoring of surface deformation with high precision, high resolution and low cost. The early Differential Interferometry Synthetic Aperture Radar (D-InSAR) technology based on the principle of interference was affected by negative factors such as time-space decoherence, atmospheric delay, and mountain vegetation, and its application in the southwest mountainous area was greatly restricted [8]. The Short Baseline Subset InSAR (Small Baseline Subset InSAR, SBAS-InSAR) technology can make full use of multi-scene radar images and time series analysis technology to effectively solve the problem of spatiotemporal decoherence and atmospheric factors in D-InSAR technology that affect the monitoring accuracy. Long-term monitoring of surface deformation, reducing the impact of space-time decoherence and atmospheric effects, can increase the monitoring accuracy to millimeter level [9] [10], which has broken through the limitations 
of D-InSAR technology to a large extent, and greatly increased the use of InSAR technology in geology. It greatly increases the application potential of InSAR Technology in geological hazard monitoring [11] [12].

The SBAS-InSAR technology is used to obtain the deformation sequence and average deformation rate of the core scenic area before and after the Jiuzhaigou earthquake. It mainly studies the changes in the core landscape after the earthquake, during and after the repair. The SBAS-InSAR technology has a wide range and high accuracy. It is not affected by weather conditions and other advantages, dynamically monitoring the effect of Jiuzhaigou restoration and conservation, provides a new means for Jiuzhaigou restoration and conservation, and is of great significance to guarantee the restoration of Jiuzhaigou scenic spots and the continuation of the landscape value.

\section{Overview of the Study Area and Data Basis}

\subsection{Overview of the Study Area}

Jiuzhaigou is located in Zhangzha Town, Jiuzhaigou County, with geographic coordinates of $100^{\circ} 30^{\prime}-104^{\circ} 27^{\prime}$ east longitude (E) and $30^{\circ} 35^{\prime}-34^{\circ} 19^{\prime}$ north latitude $(\mathrm{N})$. The landform of Jiuzhaigou is a high mountain and valley area, the terrain is high in the south and low in the north, with an altitude of 1996 - 4764 $\mathrm{m}$. The average annual precipitation is $646 \mathrm{~mm}$, the average annual temperature in the scenic area is $7.3^{\circ} \mathrm{C}$, and the average temperature of the hottest month (July) and coldest month (January) are $16.8^{\circ} \mathrm{C}$ and $-3.7^{\circ} \mathrm{C}$, respectively [13]. The geological conditions in the scenic area are complex, and faults are developed, and geological disasters frequently occur before the earthquake [14]. The earthquake caused direct damage to many core landscapes in the scenic area, and the study area was densely covered with vegetation. Therefore, the entire Jiuzhaigou Valley was selected as the study area to study the core earthquake-damaged landscape. The study area is shown in Figure 1.

\subsection{Data Basis}

This paper selects 10 Sentinel-1A SLC data (see Table 1). Precise Orbit Ephemendes (Precise Orbit Ephemendes) POD, POD can correct orbit information containing errors, effectively removing its systematic errors. The reference DEM uses 30-meter resolution SRTM digital elevation model data to remove the terrain phase and perform phase unwrapping. The data time span of 10 sceneries of Sentinel-1A is 2017.07.30-2020.01.28. Since the Jiuzhaigou earthquake occurred on August 08,2017 , the study time began on July 30, and the time points adopted were mainly based on the restoration period (2017.1-2018.05).

\subsection{SBAS-InSAR Technology Principle}

The short-baseline interferometry technique was proposed by Berardino and Lanari et al. in 2002 [8]. This method freely combines to generate time-series interferograms of multi-primary images according to the principle of short-time-space base- 
lines, and uses the singular value decomposition of the matrix (Singular Value Decomposition, SVD) method inversion to obtain the deformation sequence and average deformation rate during the observation period of the study area [14] [15] [16]. The SBAS processing flow is shown in Figure 1, and the corresponding calculation method refers to the literature [17] [18]. Specific steps are as follows:

1) Acquire $N+1$ scenes of SAR images in a certain time series in the study area, select one scene for registration and generate interference image pairs $M$, where $M$ is the number of interference image pairs, and the following conditions need to be met. When editing image pairs, you can remove the less relevant image pairs:

$$
\frac{(N+1)}{2} \leq M \leq N \frac{(N+1)}{2}
$$

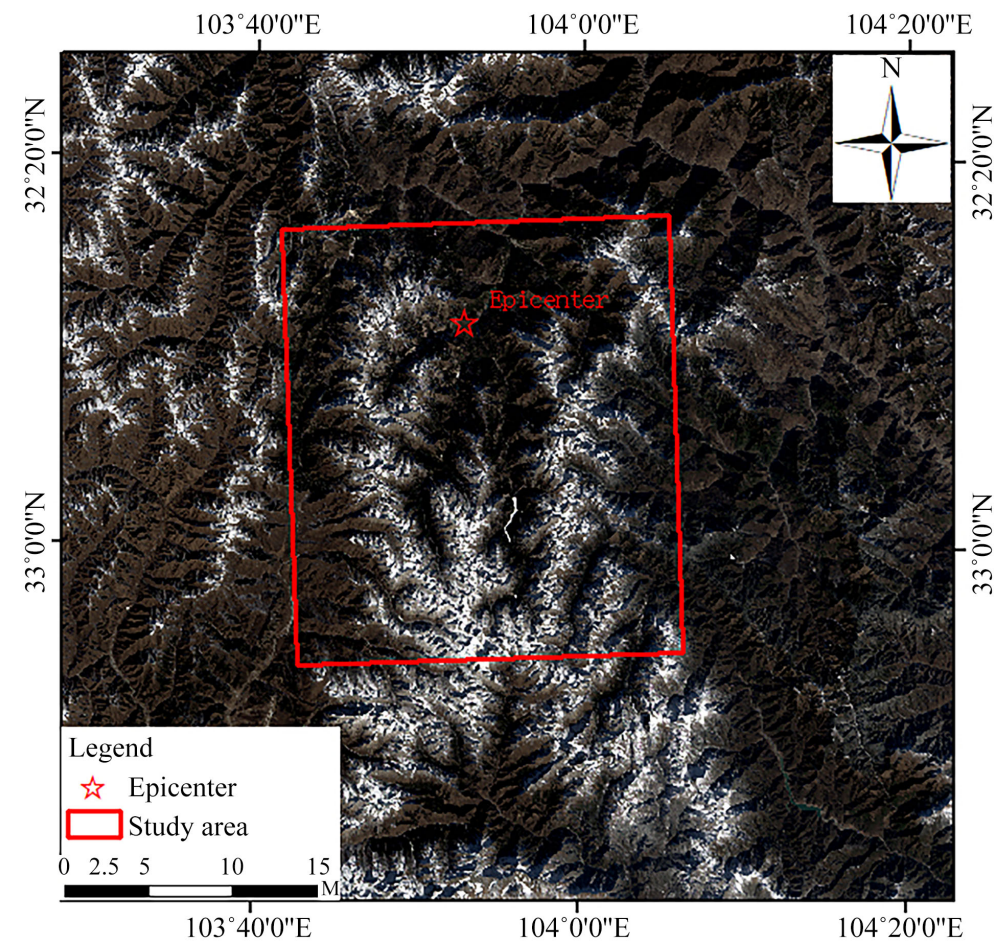

Figure 1. Study area.

Table 1. Sentinel-1a image information.

\begin{tabular}{cccc}
\hline parameter & Corresponding value & parameter & Corresponding value \\
\hline Orbital direction & Ascending & Band & $\mathrm{C}$ \\
Imaging mode & $\mathrm{IW}$ & Wavelength $/ \mathrm{cm}$ & 5.6 \\
Polarization mode & $\mathrm{VV}$ & Resolution $/ \mathrm{m}$ & $5 \times 20$ \\
Revisit cycle & $12 \mathrm{~d}$ & Incident angle $/\left(^{\circ}\right)$ & $39.6^{\circ}$ \\
images/scene & 10 & Image time & $2017.07-2020.01$ \\
\hline
\end{tabular}


2) Interference processing is performed on the paired images, and the differential interferogram generated by combination is used for phase unwrapping using orbit parameters, reference DEM and filtering. There are many methods for phase unwrapping, including region growth method. Delaunay MCF method composed of irregular triangles and minimum cost flow method. In this paper, the Delaunay MCF method is selected and 3D unwrapping is performed. The orbit parameters and reference DEM are added to remove most of the phase error caused by the terrain and the phase error caused by the influence of noise. Relatively remove those that are greatly affected by the atmosphere, poor coherence, or poor unwrapping results;

3) In SBAS processing, GCP is used to re-level all data pairs. Select no less than 20 control points for orbit refining and re-leveling. GCP needs to select no residual terrain stripes, no deformation stripes. There are no phase jump points. If you can't choose a perfect GCP point, choose as many as possible. Flattening includes orbit optimization and residual phase optimization. In this paper, the residual phase optimization method is selected to optimize the flattening process;

4) SBAS performs two inversions. The first is to estimate the residual topography and deformation rate, and the second entanglement is performed to optimize the interferogram results, and the second is to effectively remove the errors caused by the atmosphere and topography to obtain higher accuracy. Calculate the displacement on the time series;

5) Perform geocoding to convert radar data from the slant-range coordinate system to the geographic coordinate system, so as to obtain the time deformation sequence and the average deformation rate in the geographic coordinate system [19] [20] [21] [22].

\section{Earthquake-Damaged Landscape Reconnaissance Analysis and Restoration and Conservation}

\subsection{Earthquake-Damaged Landscape Reconnaissance Analysis}

The Jiuzhaigou Restoration and Conservation Task Force conducted the first survey of the Jiuzhaigou scenic spot on October 18, 2017, mainly focusing on the three core scenic spots: Sparkling Sea, Nuorilang Waterfall and Panda Sea. In October 2017, site surveys and geophysical prospecting work were carried out on the sparkling sea and Nuorilang waterfall in Jiuzhaigou. Geophysical prospecting uses high-density electrical methods and radar geophysical prospecting to conduct geophysical surveys on the interior and front and rear dams of the Sparkling Sea, the entire front edge of Nuorilang Waterfall, the Panda Sea dam and its surrounding facilities. The sea of sparks is located at the beginning of the scenic tourist route. After the earthquake, the sea of sparks broke the dike shockingly. The lake of $450 \times 103 \mathrm{~m}^{3}$ disappeared instantly, leaving behind the exposed travertine dam and travertine reef. Nuorilang Waterfall has undergone more than 30,000 years of waterfall effect, forming the existing Nuorilang Wa- 
terfall landscape. After the earthquake, a "U-shaped" crack $(0.7 \mathrm{~m} \times 7.2 \mathrm{~m})$ appeared in the dam above the outflow of Nuorilang Waterfall. The length of the dam crest fissure is about $20 \mathrm{~m}$, resulting in the lack of waterfalls with a width of about $50 \mathrm{~m}$ on the crest of the dam, all of which seriously affect its visualization effect. At the same time, the Nuorilang Waterfall dam has existing water-containing, water-free cavities and fissures, which may bring risks such as new piping and secondary collapse. Landfills and landslides on both sides have reduced the area of Panda Lake, which directly affects the viewing of tourists. The natural construction of travertine dams includes multiple functions such as plant trunk accumulation and interception, travertine debris stacking, and travertine in-situ deposition. Its formation has long-term and particular characteristics. In view of the current surface water chemistry and surrounding environmental conditions, the natural damming behavior is irreversible after damage behavior is irreversible after damage. It can be seen that the restoration of the core landscape damaged by the earthquake is very urgent and necessary. From October to December 2017, the exploration analysis and geophysical prospecting of the three core landscapes were completed. In March 2018, on-site surveys and supplementary surveys of the three core landscapes were carried out again. Nuorilang Waterfall officially completed the restoration of the top of the dam on May 23, 2018.

\subsection{Landscape Restoration and Conservation}

1) In accordance with the basic principle of "respect for nature and moderate intervention", the restoration of the earthquake-damaged area at the core heritage site of Jiuzhaigou, based on exploration and analysis, uses the following methods to restore and conserve the core earthquake-damaged landscape of Jiuzhaigou.

2) After the earthquake, the Sea of Sparks was seriously damaged, the dam on the side of the Shuanglong Sea collapsed, and the landscape changed from lake to stream and calcification collapse. First, use the slope to clean up debris, manually excavate collapse and calcification, process calcification raw materials, and make calcification repair agent. Afterwards, measures such as slope leveling and dam bottoming, side slope repair, dam repair, and tunnel closure and water storage will be carried out.

3) Nuorilang Waterfall dam body piping flow mainly comes from cracks in the dam crest, so the restoration and conservation of Nuorilang Waterfall is mainly the repair of the crest funnel of the damaged section, the repair of the damaged surface of the piping and the cracks in the dam body and the restoration of natural maintenance.

4) Landfills and landslides on both sides have caused the area of the Panda Sea Lake to be reduced on the original basis. The Panda Sea landscape needs to strengthen disaster management and the cleaning of lakeshore deposits to restore the Panda Sea to its original state as much as possible. 


\section{Result Analysis and Discussion}

Since the three core earthquake-damaged landscapes were surveyed in October, December and March of the following year after the earthquake, the Nuorilang Waterfall dam crest restoration work was completed in May 2018. This article selects the corresponding date image data and uses the above processing methods. Obtain the cumulative settlement of the core scenic spot and the monthly average settlement rate. This article mainly analyzes the three core earthquake-damaged landscapes of the Sparkling Sea, the Panda Sea and the Nuorilang Waterfall. Using SBAS-InSAR technology, the settlement accumulation diagram and the settlement rate of the above three scenic spots in the settlement sequence are obtained (as shown in Figure 2 and Figure 3).

As shown in Figure 2, after the earthquake occurred on August 8, 2017, the monthly average settlement rate of the three core earthquake-damaged landscapes increased rapidly in the negative direction, and Nuorilang Falls reached a maximum of $107.5 \mathrm{~mm} / \mathrm{s}$, indicating that rapid surface settlement occurred and the amount of settlement When it reaches $43 \mathrm{~mm}$, the settlement rate decreases after the earthquake. At the same time, the cumulative settlement of the three scenic spots increased. Among them, Nuorilang Waterfall has the largest cumulative settlement, with a maximum settlement of $50 \mathrm{~mm}$, indicating that a large settlement has occurred in this area. In October 2017, the exploration and restoration of Nuorilang Waterfall and the Sea of Sparks began. By December 2017, the exploration of the three core earthquake-damaged landscapes was basically completed. It can be seen from Figure 3 shows that the monthly average subsidence rate of the three restoration sites decreased rapidly after August, and increased first and then decreased around October, and the subsidence rate tended to zero around December. After the earthquake, the cumulative subsidence of the three scenic spots increased first and began to decrease after October. Among them, the Panda Sea changed the most, and the cumulative subsidence of Nuorilang Falls decreased significantly after restoration. During the restoration period, the cumulative subsidence of the sea of sparks decreased first and then increased, but it also decreased compared to after the earthquake. After December, the monthly average subsidence rate of Nuorilang Waterfall and Panda Sea stabilized and approached 0 , and there was basically no change after that. The monthly average rate of Spark Sea was still fluctuating up and down, but the rate was relatively small at $6 \mathrm{~mm} / \mathrm{s}$. It started to decrease after 2018.05 .30 and stabilized around 2019. During the period from 2017.12 to 2018.05, when the restoration measures were taken, the settlement of Panda Sea and Nuorilang Waterfall stabilized, and the accumulated settlement did not change much. The settlement of Spark Sea first decreased and then increased, and it will be constant after May. Stable over time. However, the settlement of the Sea of Sparks has not decreased relatively. The settlements of Nuorilang Waterfall and Panda Sea have been decreasing until the restoration period in May. By 5.26, the accumulated settlement of Panda Sea was only $12 \mathrm{~mm}$, and Nuorilang Waterfall was $22 \mathrm{~mm}$. 


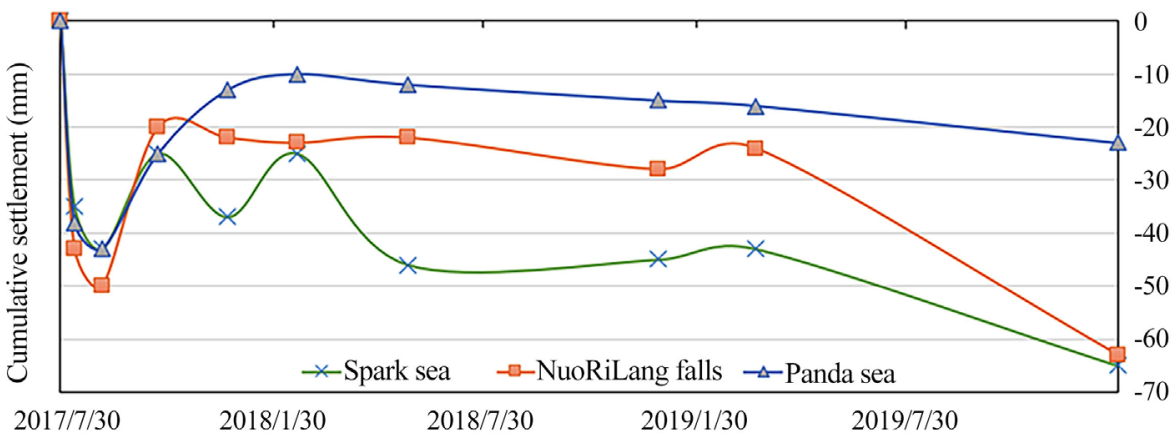

Figure 2. Accumulated settlement.

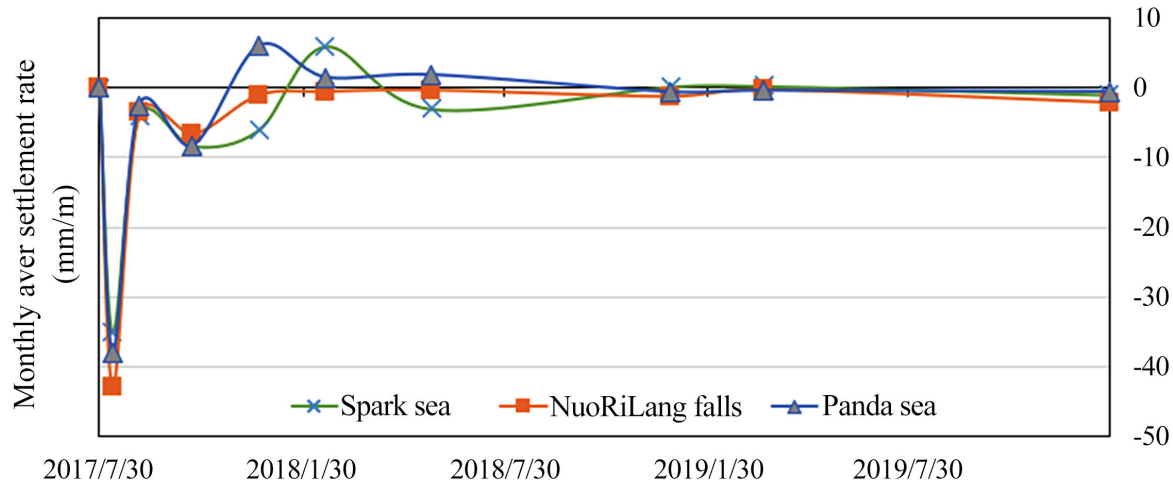

Figure 3. Monthly average settlement rate.

It shows that the corresponding measures taken according to the earthquake-damaged landscape are very effective. After the restoration and conservation, the earthquake-damaged landscape has not changed much, and there are no more disasters such as settlement.

Figure 4 shows the cumulative sedimentation diagram at the time points of 2017.08.11, 2017.10.22, 2018.05.26, 2020.01.28 (from left to right, from top to bottom) and Figure 5 shows the rate change diagram. The famous landscapes of Jiuzhaigou are all near the three ditch. Cumulative settlement of the three core earthquake damaged landscapes on August 11, 2017. The maximum cumulative settlement in this figure is $43 \mathrm{~mm}$. After the earthquake, the three scenic spots and surrounding areas have experienced significant settlements, and some areas have suffered heavy settlements. However, after the restoration, it can be clearly observed that the cumulative settlement of the three core earthquake-damaged landscapes is decreasing, but in terms of the settlement rate, the settlement of the three scenic spots has occurred. According to the restoration date, it can be seen that during the restoration period, the cumulative settlements of the three core earthquake-damaged landscapes and certain scenic spots in the surrounding area are all decreasing, and the effect is obvious. As for the cumulative settlement on February 28, 2020.01, reaching the maximum settlement of $65 \mathrm{~mm}$, it indicates that the Jiuzhaigou core earthquake-damaged landscape is changing and can be further studied based on the new monitoring results. 

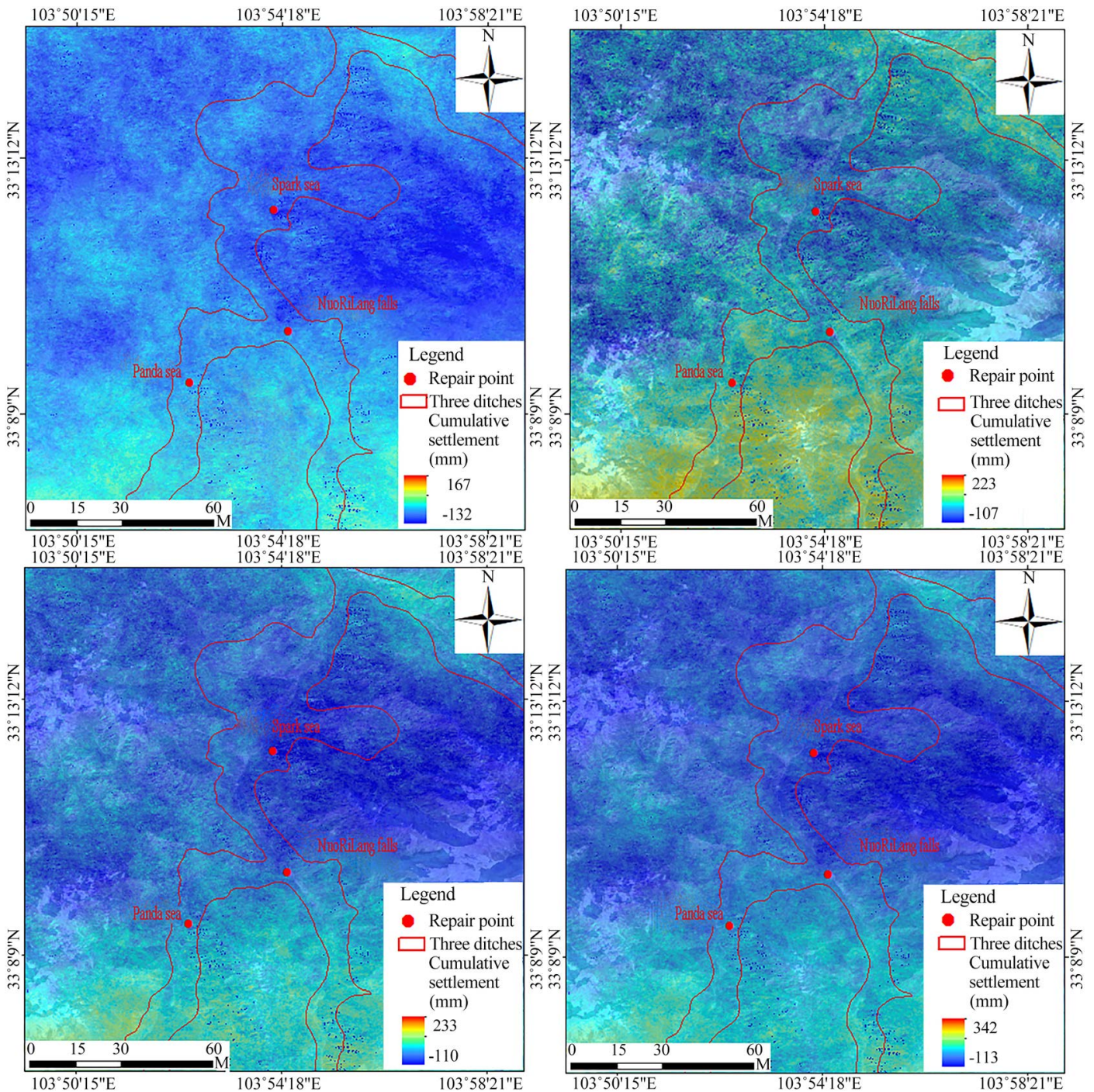

Figure 4. Cumulative settlement of three core scenic spots.

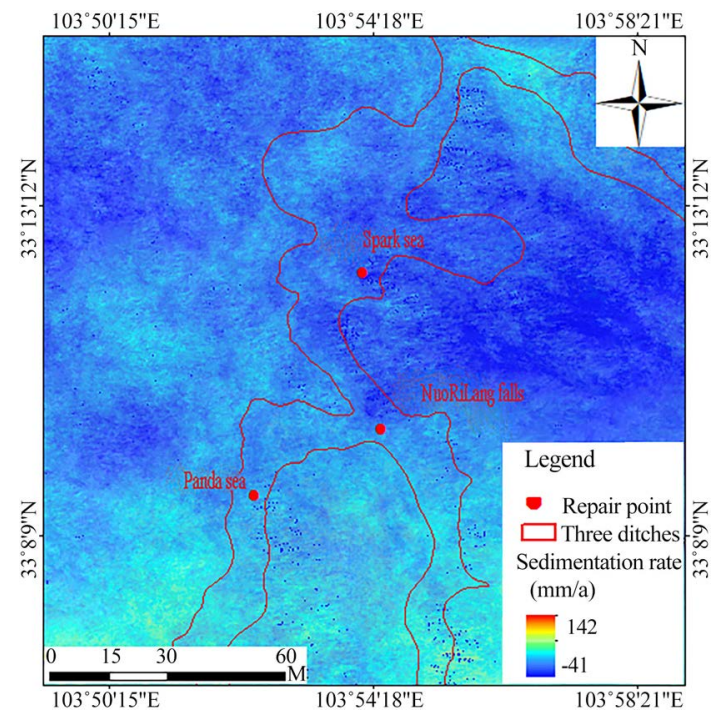

Figure 5. Settlement rate of three core scenic spots. 


\section{Summary}

This paper uses SBAS-InSAR technology to obtain the settlement results of important scenic spots in Jiuzhaigou Scenic Area around 2017.08.08. The main conclusions are as follows:

1) After the earthquake, geological disasters such as mudslides and collapses occurred in a large number of scenic spots in the study area, especially the core landscapes of Spark Sea, Panda Sea, and Nuorilang Waterfall. The damage was serious. After the earthquake, the ground subsided rapidly, with a settlement amount of $43 \mathrm{~mm}$. The maximum monthly average velocity changed to 107.5 $\mathrm{mm} / \mathrm{s}$. During the restoration period from 2017.07 to 2018.05, the elevations of the three locations showed a downward trend, but the settlement decreased significantly after the restoration, and the settlement rate also decreased significantly, approaching 0 , indicating that the restoration effect is good.

2) SBAS-InSAR technology can obtain a large range of time series deformation, as well as a small area of settlement rate, with an accuracy of $\mathrm{mm}$ level. Long-term dynamic monitoring can be carried out after the restoration and conservation of the Jiuzhaigou scenic spot to reflect its restoration and conservation effect on the one hand. SBAS-InSAR technology can not only monitor the deformation of earthquake disasters, but also dynamically monitor and analyze the restoration of earthquake scenic spots by obtaining surface deformation information with high temporal and spatial resolution. The continuation of the landscape value is of great significance.

3) Through analysis and verification, the results can dynamically monitor the restoration of scenic spots after the Jiuzhaigou earthquake and provide a method for the rescue and restoration of world heritage sites.

\section{Conflicts of Interest}

The authors declare no conflicts of interest.

\section{References}

[1] Hu, B., Wu, Y., Wei, D.H., Yang, B., Yu, J.P. and Chen, Z.M. (2019) Surface Deformation Monitoring after Jiuzhaigou Earthquake Based on SBAS Technology. Surveying and Mapping Engineering, 28, 30-34.

[2] She, J.X., Xu, Q., Yang, W.N., Dong, X.J. and Liu, F. (2021) Early Identification and Analysis of Hidden Dangers of Earthquake Geological Disasters in Jiuzhaigou. Journal of Engineering Geology, 1-10.

[3] Zhang, Y.S., Cheng, Y.L., Yao, X., Wang, J., Wu, S.R. and Wang, M. (2013) The Formation and Evolution Process of the Wenchuan Earthquake-Landslide-Debris Flow Disaster Chain in Sichuan. Geological Bulletin, 32, 1900-1910.

[4] Zhang, Q.K., Ling, S.X., Li, X.N., Sun, C.W., Xu, J.X. and Huang, T. (2020) Comparative Study on the Rapid Assessment Model of Landslide Hazard Susceptibility in Jiuzhaigou County. Chinese Journal of Rock Mechanics and Engineering, 39, 1595-1610.

[5] Yuan, M.K., Song, W., Du, J., Zheng, X.M. and Zhuo, M.T. (2021) Research on the Sensitivity of the Eco-Geological Environment after the Jiuzhaigou 8.8 Earthquake 
Based on 3S Technology. Geological Journal of Sichuan, 41, 289-294.

[6] Luo, L.G., Pei, X.J., Cui, S.H., Huang, R.Q., Zhu, L. and He, Z.H. (2021) Study on the Combination Selection of the Susceptibility Evaluation Factors of Jiuzhaigou Earthquake Landslide. Chinese Journal of Rock Mechanics and Engineering, 40, 1-14.

[7] Li, D. and Hou, X. (2020) Case Analysis of Monitoring Surface Deformation Using Sentinel-1a Data. Surveying and Mapping Bulletin, No. 3, 118-122.

[8] Wang, G.J., Xie, M.W., Chai, X.Q., Wang, L.W. and Dong, C.X. (2011) Example Analysis of D-InSAR Technology in Landslide Monitoring in Reservoir Area. China Mining Industry, 20, 94-101.

[9] Casu, F., et al. (2014) SBAS-DInSAR Parallel Processing for Deformation Time-Series Computation. IEEE Journal of Selected Topics in Applied Earth Observations \& Remote Sensing, 7, 3285-3296. https://doi.org/10.1109/JSTARS.2014.2322671

[10] Ardizzonef, F., et al. (2012) Analysis of Ground Deformation Using SBAS-DInSAR Technique Applied to COSMO-SkyMed Images, the Test Case of Roma Urban Area. SAR Image Analysis, Modeling, and Techniques XII, Vol. 8536, 85360D. https://doi.org/10.1117/12.979388

[11] Li, K.W., Chen, G., Zhang, Y.S. and Ren, L. (2018) Analysis and Research on the Method of Tunnel Point Cloud Gridding. Geospatial Information, 16, 14-17+9.

[12] Wang, T., Tian, L.Y., Hou, J.M., Zhao, X. and Zhang, Y. (2018) Point Cloud Grid Filtering Method and Its Application in Tunnel Deformation Monitoring. Journal of Hohai University (Natural Science Edition), 46, 451-457.

[13] Hu, X.D., Hu, K.H., Tang, J.B., You, Y. and Wu, C.H. (2019) Assessment of Debris-Flow Potential Dangers in the Jiuzhaigou Valley Following the August 8, 2017, Jiuzhaigou Earthquake, Western China. Engineering Geology, 256, 57-66. https://doi.org/10.1016/j.enggeo.2019.05.004

[14] Berardino, P., Fornaro, G., Lanari, R., et al. (2002) A New Algorithm for Surface Deformation Monitoring Based on Small Baseline Differential SAR Interferograms. IEEE Transactions on Geoscience and Remote Sensing, 40, 2375-2383. https://doi.org/10.1109/TGRS.2002.803792

[15] Ran, P.L., Li, S.D., Yang, X.X., Dai, K.R. and Gou, J.S. (2021) Land Subsidence Monitoring in Xi'an Based on SBAS-InSAR Technology. Journal of Henan Polytechnic University (Natural Science Edition), 40, 66-74.

[16] Peng, M.M., Zhao, C.Y., Zhang, Q., et al. (2019) Research on Spatiotemporal Land Deformation (2012-2018) over Xi'an, China, with Multi-Sensor SAR Datasets. Remote Sensing, 11, 664. https://doi.org/10.3390/rs11060664

[17] Hu, L.Y., Zhang, J.F. and Shang, X.Q. (2010) The Principle of SBAS-InSAR Technology and Its Application in Crustal Deformation Monitoring. Collected Works of Crustal Tectonics and Crustal Stress, 82-89.

[18] Yin, H.J., Zhu, J.J., Li, Z.W., Ding, X.L. and Wang, C.C. (2011) Research on Mine Deformation Monitoring Based on SBAS. Journal of Surveying and Mapping, 40, 52-58.

[19] Zhang, Y.M., Wang, P., Luo, X., Zhang, Q. and Chen, H. (2017) Using Sentinel-1 Data and SBAS-InSAR Technology to Monitor Xi' an Surface Subsidence. Bulletin of Surveying and Mapping, No. 4, 93-97.

[20] Li, S.S., Li, Z.W., Hu, J., Sun, Q. and Yu, X.Y. (2013) SBAS-InSAR Technology to Monitor Seasonal Frozen Soil Deformation on the Qinghai-Tibet Plateau. Chinese Journal of Geophysics, 56, 1476-1486.

[21] Wang, Z.H., Ren, J.T., Fan, C.C., Liu, J.B. and Lei, Y. (2021) Applicability Analysis 
of Sentinel-1A in Surface Subsidence Monitoring in Southwest Coal Mining Area. Progress in Geophysics, 1-15.

[22] Wang, J., Qi, X.B., Wang, L.H. and Wang, Z.H. (2021) Application of SBAS-InSAR Technology in Surface Subsidence Monitoring of Mining Areas. Beijing Surveying and Mapping, 35, 548-552. 